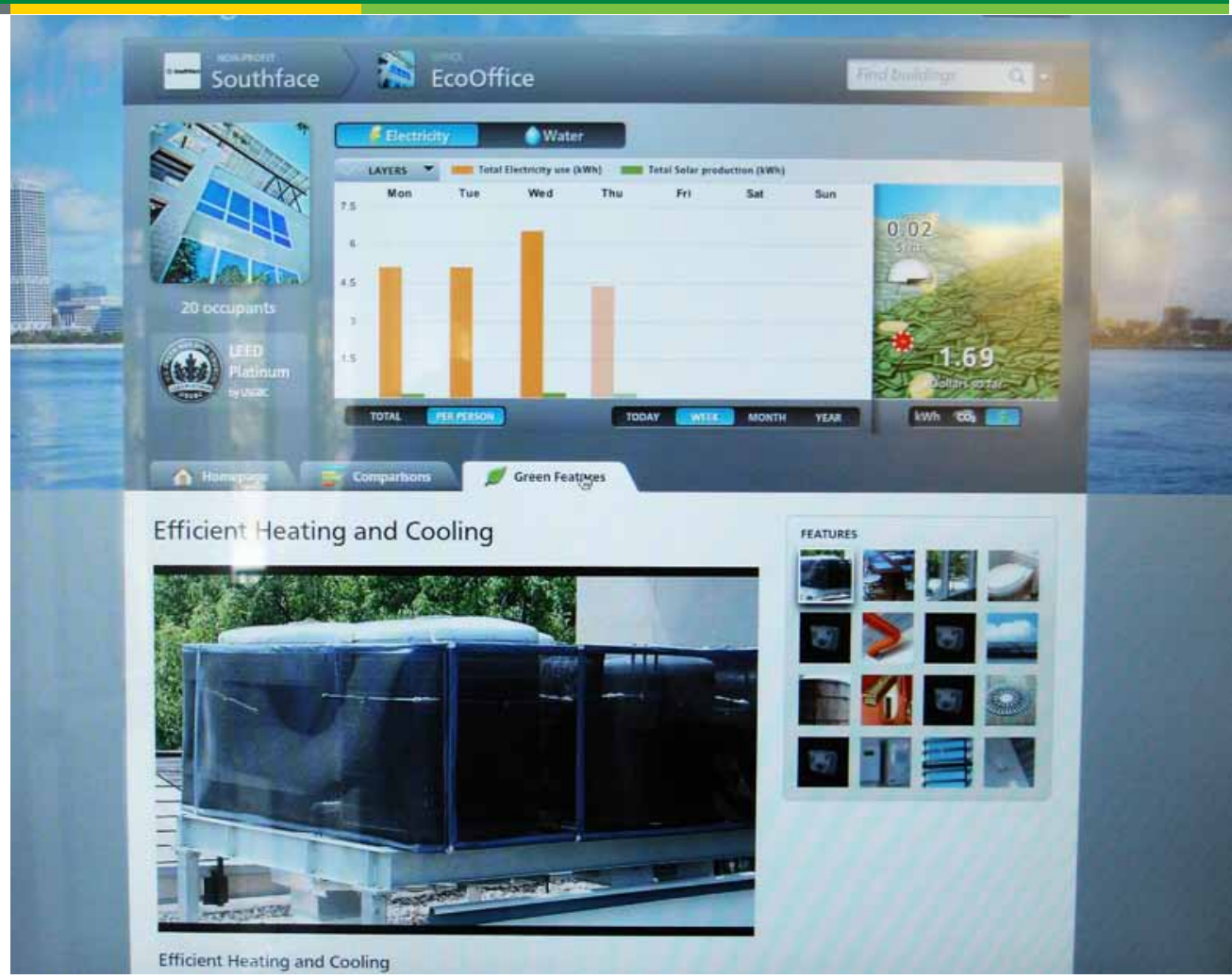

\title{
Achieving Energy Efficiency Through Real-Time Feedback
}




\section{Achieving Energy Efficiency Through Real-Time Feedback}

Prepared by

Pacific Northwest National Laboratory

Ron Nesse and Michael Baechler

\section{ARUP}

Cole Roberts and Jason McDermott

September 27, 2011

Prepared for

U.S. Department of Energy

under Contract DE-AC05-76RL01830

PNNL-20930

Pacific Northwest National Laboratory Richland, Washington 99352

This report was prepared as an account of work sponsored by an agency of the United States Government. Neither the United States Government nor any agency thereof, nor Battelle Memorial Institute, nor any of their employees, makes any warranty, express or implied, or assumes any legal liability or responsibility for the accuracy, completeness, or usefulness of any information, apparatus, product, or process disclosed, or represents that its use would not infringe privately owned rights. Reference herein to any specific commercial product, process, or service by trade name, trademark, manufacturer, or otherwise does not necessarily constitute or imply its endorsement, recommendation, or favoring by the United States Government or any agency thereof, or Battelle Memorial Institute. The views and opinions of authors expressed herein do not necessarily state or reflect those of the United States

Government or any agency thereof. 


\section{Contents}

Achieving Energy Efficiency Through Real-Time Feedback ............................... 1

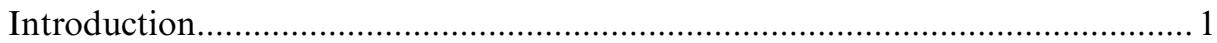

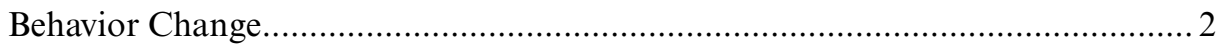

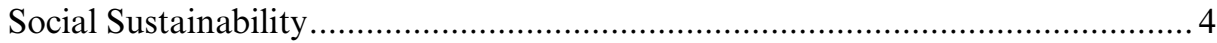

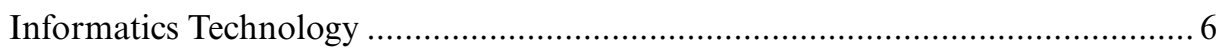

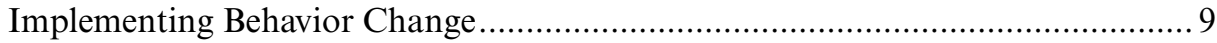

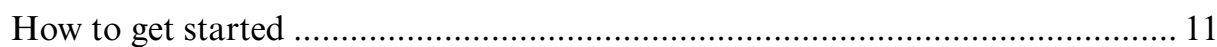

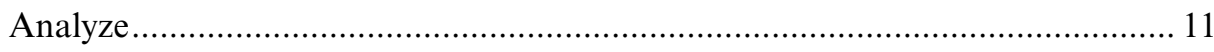

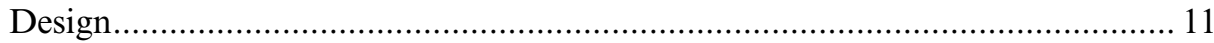

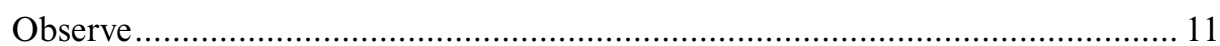

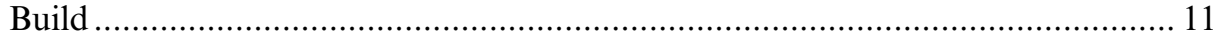




\section{Achieving Energy Efficiency Through Real-Time Feedback}

\section{Introduction}

There are several major challenges around energy efficiency. Motivation for change is perhaps the most complex, requiring engagement in not only information, but translation of abstract data into meaningful information for people to use, and tools to help them make a positive impact. The need for positive, supporting messaging is important. A 2009 international study in Copenhagen, showed that whilst a large majority of people agree that global temperature has risen in the last 100 years as a result of human activity, only a smaller percentage felt that anything could be done to change this. One quarter of this same group reported a zero Willingness To Pay (WTP) for energy reductions of up to $85 \%$ of the current levels. A 2009 study by the Lowy Institute in Australia also showed the number of people willing to shoulder "significant costs" to tackle global warming had fallen to $48 \%$ since 2006, a drop of $20 \%$.

Part of this unwillingness to tackle energy efficiency or climate change may not be simply due to a lack of willpower around sustainable living, but a form of inaction and fatigue due to an over-communication of abstract data, providing little or no relevant understanding to help communities build their own knowledge, resilience and ownership of energy efficiency - and

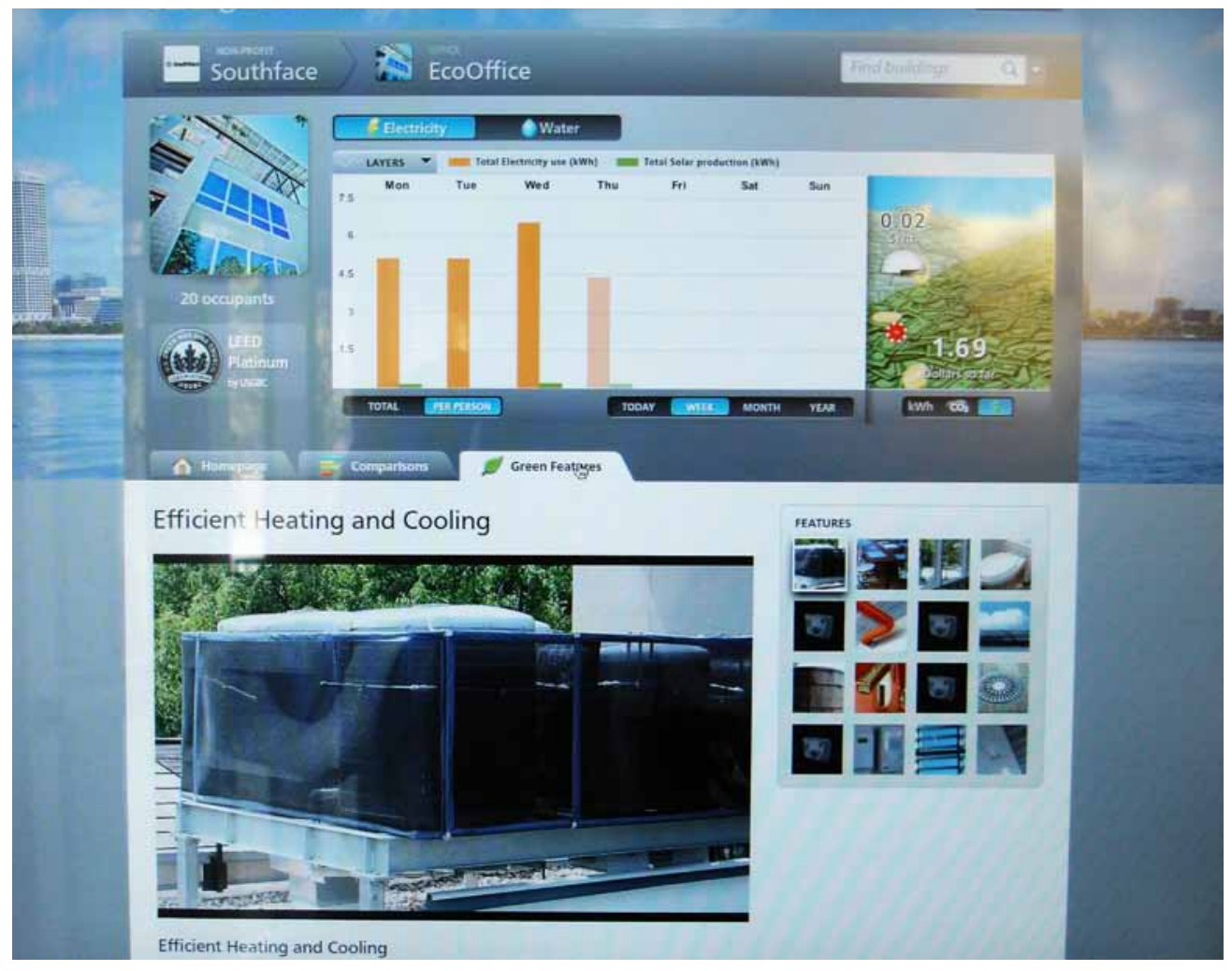

Southface, a nonprofit energy efficiency organization, uses interactive dashboards to inform users about building energy and environmental performance.

how this can impact on a sustainable future. In a culture where people readily respond to social influence and narrative, more so than data alone, it's clear the solution isn't only about information, but the way in which it's communicated.

The energy life cycle of a commercial building mainly follows three phases; i.) the building design, ii.) the construction and embodied material energy, and iii.) the ongoing occupancy or life of the building. Those who use the building most (operators, visitors, tenants and the like) only ever impact on the third phase - the ongoing life of a building - which is the focus of this user guide. Energy efficient building occupancy gains can be made through a supported behavior change strategy, incorporating deliberate placement of real-time energy use feedback for building users.

Through the careful implementation of simple behavior change measures, opportunities exist to achieve strategic gains, including greater operational efficiencies, energy cost savings, greater tenant health and ensuing productivity and an improved brand value through sustainability messaging and achievement. 


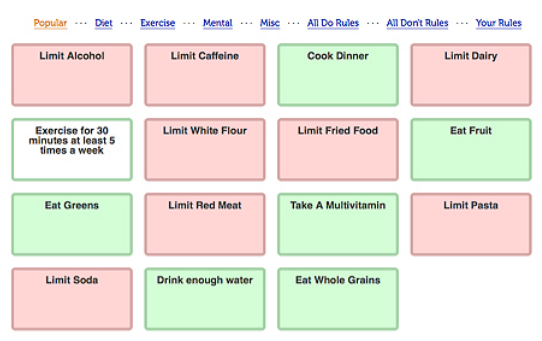

\section{HEALTH MONTH}

Health Month is game to help improve your diet, fitness, mental health, while enjoying it. Aimed at helping users set and maintain small goals, Health Month rewards achievement with small incentives (digital fruit). Health month uses both social and reward incentives to encourage long term commitment to new behaviors. www.healthmonth.com

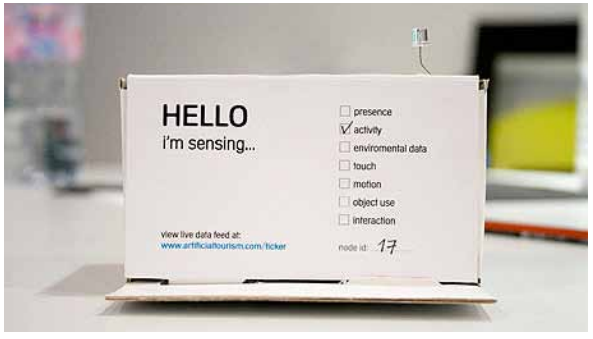

\section{MAKING SENSE OF SPACE}

A series of interface designs aimed at experimenting with more real-time interaction between a building and it's users. Each interface provided an unexpected means of communicating experience, with small levers posing questions like "are you hot or cold?" to users.

www.artificialtourism.com/bop-intelligentworkplace-visualisation/

\section{Behavior Change}

Why commercial buildings matter \& why behavior is so important.

In 2010 , buildings in the US accounted for $74.1 \%$ of the total annual electricity consumption with commercial buildings alone responsible for $47.8 \%$. Typically, energy accounts are one of the highest single operational cost to an organization, with up to $47 \%^{1}$ of this being attributed directly to occupancy-generated activity such as lighting, heating \& cooling. These loads, whilst necessary to facilitate productive working environments, are an area where small gains can amount to significant annual savings.

For some people, up to $90 \%$ of their working hours will be spent indoors, in tightly controlled office environments. For these people, many aspects of energy efficiency will be out of their control (like heating systems or energy sources), whilst some others might not even register as decisions. Default behavior-leaving lights on-contribute to energy inefficiency, and are areas in which gains can be made. Targeting small behavior change with real-time feedback offers potential to achieve ongoing savings. Supported occupancy behavior can also unlock hidden energy savings by empowering a community to control their energy use more efficiently.

\section{Why Target Behavior?}

\section{Simple Gains - targeting existing inefficient energy use can achieve savings in small, incremental steps.}

Implementing simple energy feedback measures will result in small energy cost savings, which can amount to significant savings over time. Studies in domestic settings have shown simple energy use feedback can introduce savings of $15 \%$ (Darby, S, 2006) or higher. Simply through providing energy use information, where usage occurs (and is higher than benchmarks or historical use), will allow users to identify and modify their own behavior. Real time energy efficiency feedback will allow for each building user to become an informed and aware contributor, helping shape energy efficiency through small and incremental behavior change.

\section{Investment \& Return - behavior change measures involve minimal new infrastructure with short payback periods.}

Occupancy behavior analysis and energy auditing will help identify areas where behavior change could be most effective, allowing measures to be highly targeted and strategic in implementation - placing measures where the biggest energy efficiency gains can be made. Furthermore, the actual cost of behavior change infrastructure is minimal compared to investment in modifications to existing or new building services. Measures can be built on top of existing services, providing useful and up to date information for building occupants to shape energy efficient behavior. Behavior driven energy efficiencies also drive associated cost savings, with a return on the investment over a small number of years. Compared to comparable building services infrastructure investment, behavior change investment periods can be as much as 3-5 times shorter ${ }^{2}$. 


\section{Attracting Tenants - efficient buildings can be attractive, for economic and ancillary benefits.}

Cost savings influenced by energy efficiency in building design and occupancy can be passed on to building tenants, which can be a strong economic driver for attracting and retaining building tenants. Cost savings from energy efficiency can come through a decrease in annual energy demand, along with indirect ancillary benefits like reduced effort by facilities management staff, increased productivity from lower staff-downtime and collaborative energy efficiency management.

\section{Influencing Behavior}

In commercial buildings, there are many different user types (owner, operator, user, visitor), each with different needs, values and abilities. Influencing each of these users, requires an understanding of how these needs and values drive behavior. Designing for influence requires analysis, identification of target behaviors and how these behaviors map to existing activity.

Stanford behavior researcher BJ Fogg has developed a tool to help understand and influence behavior, the Fogg Behavior Model (FBM). The FBM is a framework for analyzing behaviors, and how they can be influenced. The FBM describes nine strategies to influence different behavior types (e.g. existing or new behavior) and aspired behavior uptake (do once or from now on). This illustrates the need for user specific information design when approaching behavior change, and the tools required to influence behavior.

The FBM identifies 3 essential elements needed to exert influence over behavior;

- Motivation - high or low

- Ability - is it easy or hard?

- Trigger - a reminder or prompt

For each user type being influenced, these elements will be different, but they must all be present to appropriately influence behavior.

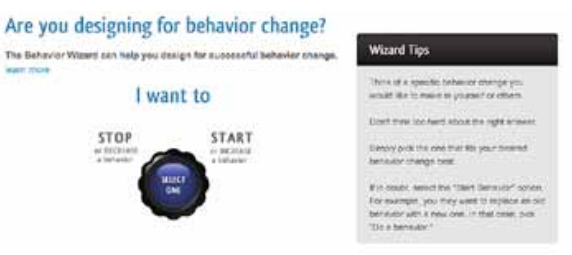

\section{FOGG BEHAVIOR WIZARD}

The Fogg behavior wizard is an online tool designed to help understand how a desired goal fits into the Behavior Grid framework, developed by BJ Fogg. It asks a series of simple questions about the behavior in question, guiding towards an appropriate behavior change strategy for the chosen behavior pattern and duration. www.behaviorwizard.org/wp/

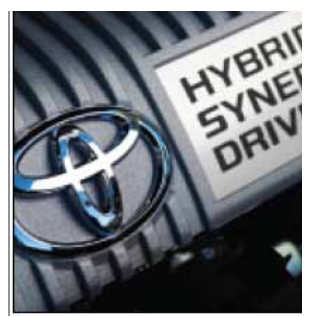

\section{TOYOTA PRIUS}

A real-time feedback loop established between driver and vehicle has encouraged drivers to consider fuel economy as they drive. Information is placed in front of the driver, where they are able to best make use of it. The clear link between driver action and energy outcome create a closed loop between action and consequence. 


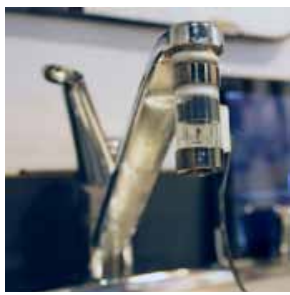

\section{TEAGUE DESIGN}

Recently Teague teamed up with FastCo Design to address the high levels of water use in the office. Initial dashboard designs maintained an interface on the staff computers but yielded no results. Teague then placed the feedback directly in front of the tap, resulting in an immediate water use reduction of $75 \%$.

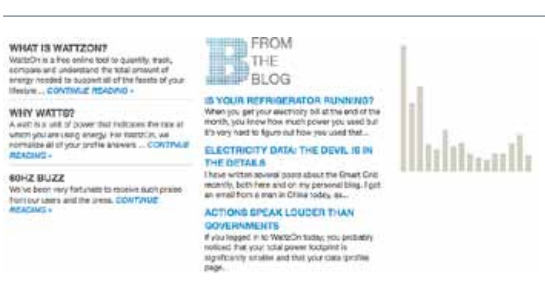

\section{WATTZON}

WattzOn is an online tool and social community focussed on giving people the tools necessary to understand and measure the total energy needed to sustain their lifestyle. The tool aims to connect users with their personal consumption, with the goal of helping people make small changes through better, clearer information.

Right: An example energy use profile, showing annual daily energy over time ( $x$ axis), and energy use in megajoules (y axis). Highlighted in blue are electricity Lighting and Equipment Plug Loads, two key areas of occupancy behavior change.

\section{Social Sustainability}

\section{Supported behavior change through influential social proof}

In addition to informing building occupants around building energy use, through a careful behavior change strategy, it's important to link this persuasive information to the social proof that others are doing so too. This is a new approach to encouraging people to actively modify their work and workplaces to create efficient environments. It's absolutely key that behavior change messaging needs to be connected to positive associations with attaining environmental sustainability whilst maintaining a high quality of life - achieving more with less.

A successful strategy will concentrate on three main themes;

\section{Providing real-time information and feedback action and effect (for instance} energy use monitoring and feedback, real time pricing), providing information at the point of decision, before it occurs, rather than in retrospect.

2. Design as research for behavior change, incorporating behavioral change models, aligning desired behaviors with appropriate persuasive strategies and adjusting these as time and behavior shifts.

3. User-centered design, information architecture and detailed interaction design, all pointed towards encouraging energy efficiency in commercial buildings.

The goal is to shift peoples' behavior towards sustainable outcomes, in a long-term, sustained fashion. Small changes, incrementally made, can lead to a significant gain in environmental quality. Behavior change is not something that can be achieved overnight, but must be built over time. Even modest shifts in occupancy behavior (between 5-25\%) will have a cumulative effect not only on the energy impact of a building, but also on the peer network, as neighbors create a lasting influence on each other. Core behavior change messages must focus on areas that building users can enact change in, following the three elements of influence from the Fogg model.

Sample areas of behavior change focus currently include;

- Electrical plug loads

- Electrical Lighting loads

- Lift use vs. internal stairs

- Electrical equipment use (computers on, outside of hours)

- Equipment on standby (phone chargers, TVs, computers)

- Personal comfort through passive means (clothing, exercise)

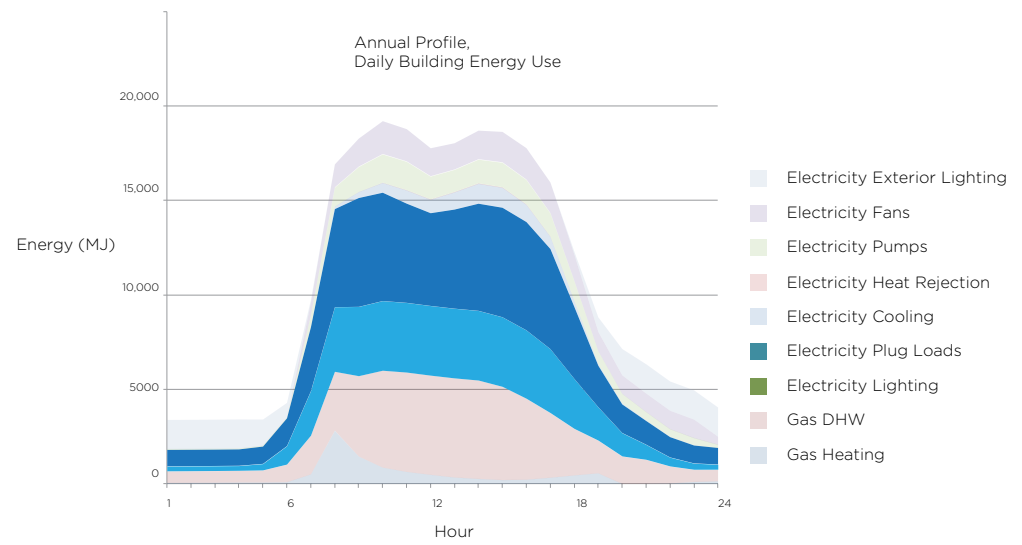




\section{Community Engagement}

By drawing the community into the creation and dissemination of their own desirable, sustainable built environments, this strategy 'outsources' some of the thinking, activity and communication, to the people who most need to engage with it - the end users, the everyday building occupants. This approach is predicated on contemporary thinking around innovation and social decision-making (Suriowiecki, J. 2004), in effect 'open sourcing' the problem solving in a collaborative, structured and methodical way. By opening up the conversation in this manner, we work towards a number of additional goals - helping people understand each others' views and knowledge in a non-judgemental setting, bringing them together to find and own a shared goal, it becomes possible for social proof to have a positive impact on the 'stickiness' of the idea. The more people involved in setting the direction for an energy efficiency initiative, the more likelihood it's aims will be core to that community, and it's solutions will be richer, more diverse than one small group could have created alone.

\section{Social Feedback}

We can draw parallels between the social interaction on a site like twitter, and the social interaction between users of a building. On Twitter or Facebook, the feedback loop between activity and response is quite clear. When a friend posts a photo, or writes a message, they do so with the tacit knowledge they are acting publicly. In contrast, building occupancy and energy use is much more sparsely connected between neighbors. Each squeeze of a doorknob, each twist of a water faucet, each button press in a lift lobby is done privately, within eyesight of only a small number of people. The key point here is not that each of these moments should be broadcast, rather that the connection is at present incredibly loose, between user and the consequences of their actions (how many gallons of water did I just use to wash my hands?).

In addition to this, the connection is poor between one user and the majority (how much water does the average handwash use?). Social norming is quite a powerful driver, it's application in suggesting sustainable behaviors to building occupants is highly promising. Good user experience design is key. Designing experiences that are surprising, engaging and compelling, help in establishing a motivation for continuing. Placing information Triggers in locations where the Ability and Motivation threshold can be overcome, is essential. Information left on a PC screen, will yield very different results compared to small feedback displays located near taps or power sockets, even though they have a shared intent.

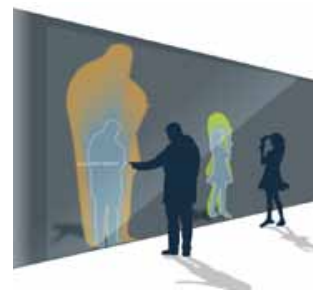

\section{HELSINKI LOW2NO}

An urban development project in Helsinki features a wide range of pervasive informatics strategies aimed at significant reduction in the carbon footprint of the community. Information services will include in-street displays that report on personal and civic footprints in real-time, smart meter concepts for apartments and displays and services that highlight patterns of behavior.

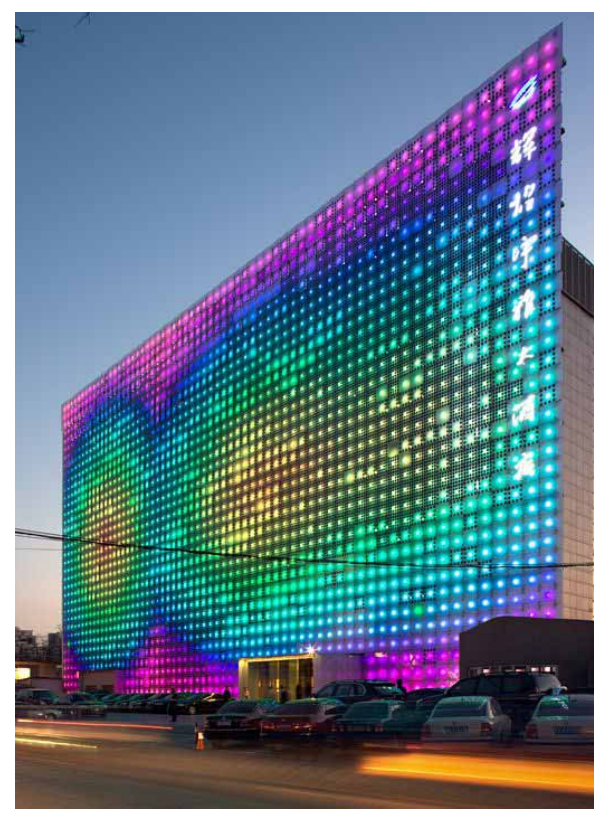

\section{GREENPIX}

GreenPix is a sustainable digital media technology curtain in Beijing. Featuring the largest color LED display worldwide, coupled with a photovoltaic system integrated into a glass curtain, the building performs as a self-sufficient organic system, harvesting solar energy by day and using it to illuminate the screen after dark. 


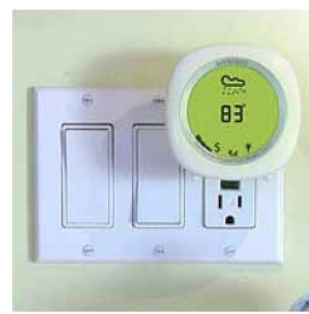

\section{SMART METERS}

Part of the Interactive Institute's

STATIC! project, poweraware is a smart way of visualising electricity usage through simple device specific feedback loops. The project aims to raise awareness of energy use through interaction design and tangible feedback.

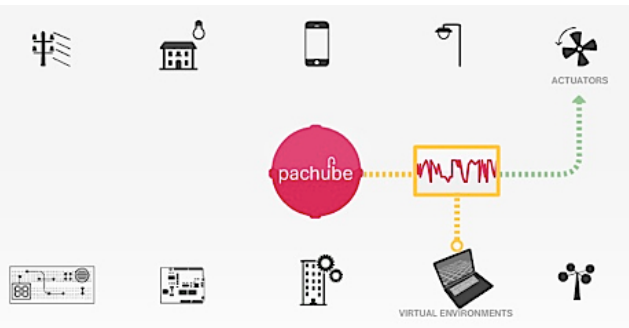

\section{ENVIRONMENTAL SENSORS}

Pachube is a data infrastructure for

the 'Internet of Things', an

interconnected network of real-time sensors logging data from around the world. Pachube manages millions of data points globally each day, sharing secure sensor data between individuals and organisations.

\section{Informatics Technology}

\section{Making invisible information visible. Making visible information actionable.}

Our environments are now more and more increasingly interconnected. Data surrounds us like never before, with unfettered access to information at our fingertips. People daily walk around with the computing power of a mid-90s desktop $\mathrm{PC}$ in their pockets. This speed of computing power and data connectivity have driven a new mentality in building users and occupants - that whilst information will be tethered to location, it will be accessible anywhere. This has dramatic impact on the way we think about how buildings interact with their occupants.

We no longer need to wait for a quarterly statement of activity to know how much energy we are consuming, we can see it as it happens. So how is it that these increases in technology are going to help us create smarter, more sustainable, resource conscious environment? Three main technologies form the foundation of any behavior change strategies to developing behavior change strategies.

\section{Smart Metering (Input)}

Smart metering simply means gathering as much data as possible, from a number of different sources. The main function of the meter is to provide a clear, consistent and comparable measurement on activity within the building, and will need to be tailored to your specific needs. There are a number of different types of smart meters, but they generally fall into three categories; building, environment and user interactive.

Buildings - Providing information measured directly from the building itself, typically through a Building Interface Control System. Common building smart meters include electricity, water and gas meters, room occupancy sensors, $\mathrm{CO}_{2}$ sensors and cameras. The location and number of these sensors will determine how focussed the building feedback can be (one per floor vs one per building). Since the smart meter is aimed at providing more real time information about building use activity, it is important that they be connected to a network and can $\log$ data in real time. There are capital costs involved in installing bespoke sensors (such as cameras or additional energy meters), however some existing building sensors will already provide adequate data for building feedback.

Environment - Providing information gathered from outside the building, typically from online and other sources, including the internet and other (related or similar) facilities. This does not involve installing or maintaining these sensors, rather using software to 'scrape' or retrieve the sensor data as it is made available. This kind of sensor data is essentially free to maintain (aside from the design and maintenance of the internet scraping software), but it does rely on external bodies maintaining the consistency and accuracy of the data itself. These data points can provide useful triggering data for healthy competition (with neighboring facilities or buildings).

User Interaction - Providing information generated solely from user activity or behavior. Traditional user interaction points have included elevator usage or RFID swipe cards, however modern technologies like Bluetooth, Wifi and touch screen devices are creating more ways for buildings and users to interact. Standard website analytics software (such as Google Analytics) allow web managers to identify paths viewers took through their site, including entry/exit points and links clicked. Through careful design and implementation of Information Architecture and Interaction Points (see below), we can create similar levels of interaction and analysis for modern buildings, showing in real time where building hot spots occur and when. Specific user activity data will be most useful in driving energy efficiency when anchored to specific energy use information, such as equipment loads or lift use. 


\section{Information Architecture (Storage \& Processing)}

The data collected by each of these sources will need to be stored and processed prior to being displayed. In order to provide building users with relevant and useful information, we need a several technologies to sort and organise data into information: an information database, processing software and a Building Interface Control System.

Information Database - holding all the data collected from each source, the information database is a key Informatics component. The database can be stored locally or remotely ('cloud' storage solutions such as Amazon A3 and Google App Engine are cheap, scalable and robust solutions), depending on your specific needs. Typical database concerns are typically centered on security around access to the raw data, reliable and continual operation ( $100 \%$ 'up time'), and flexibility for future growth or needs. The information design of the database should incorporate a structure that follows a clear structure allowing both immediate use and future flexibility.

Processing Software - The critical step between raw sensor data and meaningful information displays is the translation between measured activity and a 'human' message - something users can connect with. The processing software layer which sifts through the raw data, is tasked with analyzing it (both current and historical) and establishing trends, significant usage patterns and relating these to factors users can understand as information. Even more importantly, the software will need to place hot triggers for users to act out, requiring a level of persuasive design, as described by BJ Fogg. This software infrastructure is inherently similar to modern websites, and has very similar requirements. The software sits 'server side' (meaning remotely connected, not on the end user device), delivering data to the 'client' (end user) over the internet or a local area network (LAN). This software can be purchased as a standard 'off the shelf' kit from a growing number of building interface developers, or can be custom made to suit the behavior change context for your organization - including detailed analysis of user needs, understanding, ability and motivation.

Control System - The back-end system itself will need an interface for guiding, curating and controlling what is shown on displays. Again, this is similar to modern Content Management Systems (CMS, such as Wordpress or TypePad), in that they provide a simple, powerful platform for administrative users to change, maintain and update the displays as is necessary. The control system provides tools to maintain the Processing Software. As time passes and behavior does change, the same message will cease to be effective in driving new change. The control system will allow for new 'campaigns' to be created and implemented, using the same base data set. This control system opens up engagement possibilities with many users (potentially able to support many user accounts to building users can get individual and customized feedback) along with highly useful feedback on the performance of any one particular behavior change 'campaign'.

\section{Visualization (Output)}

Visualization simply means presenting the information to users in a compelling and useful way. Touch screen and web technologies (like the iPhone or HTML5) have made huge advances in recent years, and are now offering more high quality feedback and interaction possibilities for use in building behavior change. The three main types generally are; standard dashboards, bespoke displays and cuttingedge interfaces.

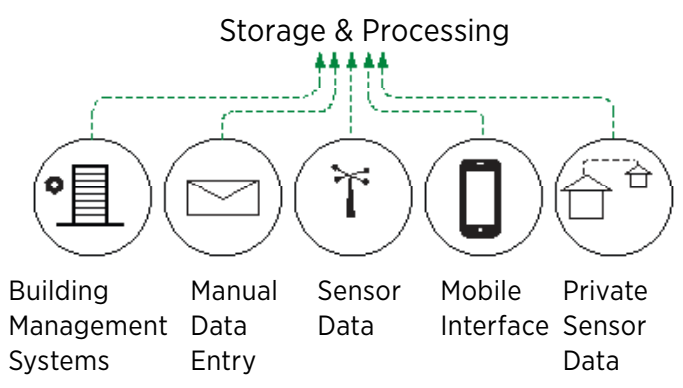

INFORMATION ARCHITECTURE

Locally stored or remotely located

(web or online data storage is more commonly called 'the cloud') data. This

needs an organisational strategy and processing software to convert data into information, for user feedback display.

\section{(11) WORDPRESS}

\section{CONTROL SOFTWARE}

Content management is an important function in behavior change. Users won't respond only to pure energy use data, rather they need a narrative connect with (how many light bulbs vs how many kilowatt hours). Wordpress is an opensource blogging CMS, providing useful and similar curatorial tools.

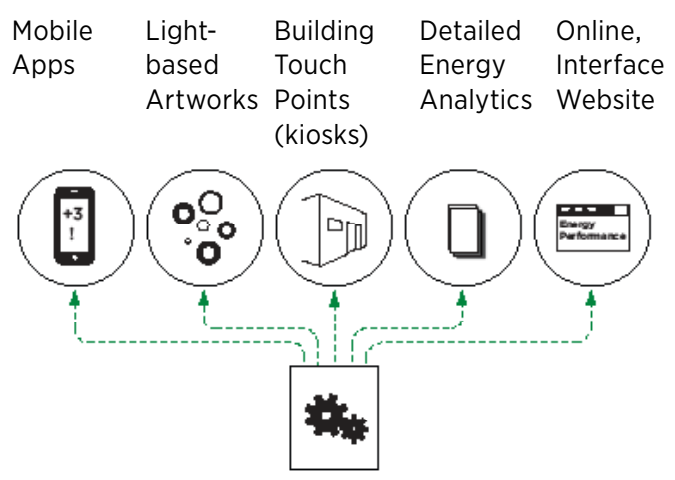




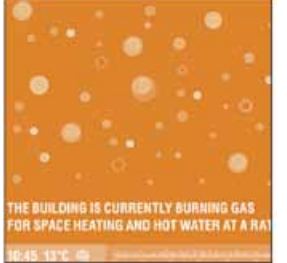

\section{DASHBOARD DISPLAYS}

Real time information displays demonstrating building energy performance for building users. Typically found in building lobbies, these also feature web displays, but tend to focus more on information (sparkline graphs or charts) than narrative. Successful dashboards include tips to help users cut down on their energy use.

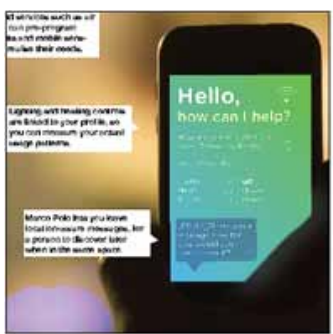

\section{BESPOKE INTERFACES}

Information displays designed to provide useful information at the point where it will be relevant. These can include specifically designed installations (such as amphibious architecture by the Living New York), or use mobile platforms for delivery.

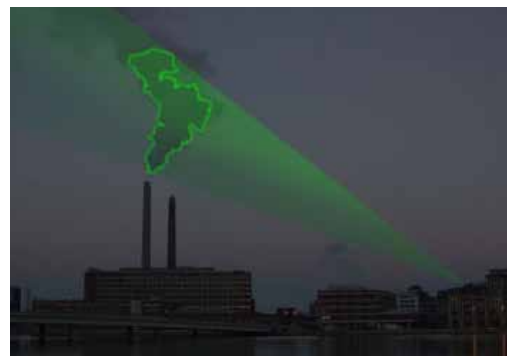

\section{CUTTING EDGE INTERFACES}

Nuage Vert is a Helsinki artwork conveys how much electricity is being used by the Salmisaari power station by shining a high-powered laser onto the cloud of smoke being emitted from the chimney, powering local homes.
Standard Dashboards - these are becoming commonplace elements in new and existing buildings - indeed there are many examples of these such screens emerging (such as at Stanford University's Y2E2 building, Harvard University's Cowperthwaite student accommodation, or the San Francisco Arup office). These displays present real time information about building energy performance and are typically found in highly visible building lobby locations. These dashboards often also feature a web-based interface, allowing the dashboard some flexibility in how it is accessed. Whilst these dashboards do offer some flexibility in the design of the material, they are often standard offerings that do not place any emphasis on behavior change models or the persuasive technologies approaches outlined earlier. It is for this reason primarily, that they are limited in scope to affect energy use behavior change.

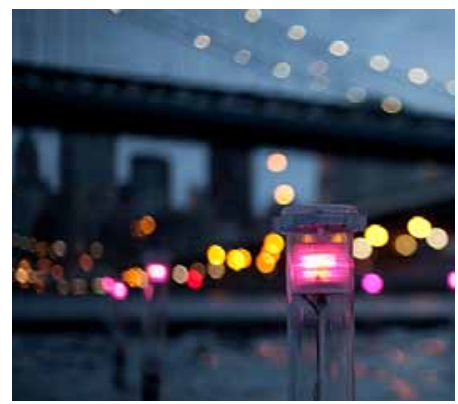

\section{BESPOKE DISPLAYS}

New york architects the living have created a floating artwork featuring an aquatic environmental feedback loop, which uses water quality and motion sensors to detect pollution and fish movement. the project aims to encourage curiosity and interest in the quality of life in the local waterways.

Bespoke displays - these are new interface types taking advantage of new advances in smart phone capabilities and new software platforms which place information closer to where we need it. Bespoke displays are much more 'user centered' than dashboards, and whilst they draw on the same set of data sources, the information they provide is much more customized to the specific needs of both the organization and the users. An example of this would be an iPhone app which ranked your energy performance against your colleagues, rewarding top performers and encouraging those with heavy usage. These displays take much more design time and research, requiring a more detailed (and case specific) understanding of the problem and how it's been addressed to date.

The internet-connected world is increasingly built on the idea of syndicating all information to web, mobile and other devices. This is known as 'cross-platform distribution', meaning that the internet enables information to be distributed to all product platforms, varying content to each device as necessary, automatically and very quickly. It is barely necessary to consider these mainstream and mature platforms individually, other than to note that any information services should be carefully designed using open standards, in order to enable the fullest possible set of devices to engage with the city.

This means designing the relevant web and mobile services - those components of the 'cloud' of information services in control of city and state governments at least to some extent - with open standards. With such an approach, it matters less whether people are trying to access services on a desktop PC, an iPad, an android phone or a laptop.

Cutting Edge Public Art - typically designed as large statements, these interfaces are unique, completely custom designs tailored to a specific context. Digital interactive artworks, such as Nuage Vert (right) emerge through partnership between many parties, including both public and private ownership. Energy efficiency through public art achieves a much looser connection between an individual and the artwork, but can have a much larger scale of influence, potentially encouraging a neighborhood or city to take a change of course. Promoting the achievements of one place to feed back to neighbors, public artworks create healthy competition, encouraging a better, healthier built environment. 


\section{Implementing Behavior Change}

\section{Case Study: Grand Valley State University}

\section{An example of energy efficiency through behavior.}

The Mary Idema Pew Learning and Information Commons at Grand Valley State University (GVSU Library) will be a landmark building for the Allendale, Michigan campus. It will be an academic and cultural hub for teaching lessons about sustainable design through examples. In addition to providing a stellar learning environment, the building will be one of the first in the country to use less than half the energy of a comparable newly constructed baseline building (as defined by ASHRAE Standard 90.1-2007). The building is being developed through an ongoing relationship with the Department of Energy Commercial Buildings Partnership (CBP) program, and is currently under construction.

Prior to the incorporation of an occupancy behavior change Energy Conservation Measure (ECM), the building design is anticipated to achieve an energy savings of $43 \%$ compared with the baseline model. A suite of ECMs were tabled through the design process, each of which were analyzed regarding i.) energy efficiency opportunity, ii.) cost of investment, iii.) estimated energy savings and investment payback period.

ECMs considered in the design phase include underfloor air distribution, LED lighting, sustainable IT purchasing processes and supported behavior change. Through detailed user analysis and energy use modelling, the supported behavior change ECM includes additional energy use metering, real time building feedback and a sustainability focused public art display.

\section{Analysis \& Opportunity}

To understand the potential energy savings available through the Behavior Change ECM, Arup analyzed the new GVSU Library with respect to i.) user groups, ii.) building usage, iii.) spatial energy use patterns, and iv.) possible energy controls. Through this process each user type is identified (casual visitors, students, faculty and University staff), and plotted on a space-use diagram to represent the spaces used most by each user type.

Each building space was modeled and analyzed to determine the energy use breakdown, pointing to i.) the energy use components for each building space, and ii.) a potential match for which user type will be most likely to influence these energy use components.

Example: Based on spatial program, the multi-purpose rooms and open-plan reading area have the highest estimated combined equipment \& lighting energy demand. For the multi-purpose spaces, it's estimated that students will use these spaces more than both University staff and casual visitors, with the inverse relationship for offices.

Areas with high energy loads also have high potential for savings made by shifting user behavior, when compared to the Fogg behavior model. In the open plan spaces, it is estimated users will have a low motivation for change, a moderate ability threshold and a need for triggers to prompt behavior. In the example of the multipurpose spaces, there are three target users; students, staff/faculty members and facilities staff. Each of these user types will have different motivation for energy efficiency, different ability to affect change, and will need suitable triggers in order to do so. Student triggers won't have the same effect on staff, and vice versa, so the design shifts for each user accordingly.

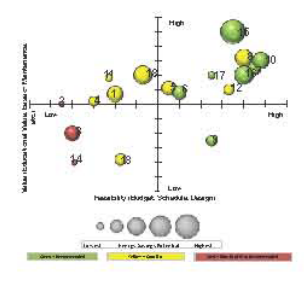

\section{STEP 1. ANALYSIS}

Detailed energy modeling and analysis of physical spaces provides rough estimates for for energy savings in each area. These estimates can then be compared to cost, annual return, payback periods and expected energy efficiency gains to assess the feasibility of each measure.

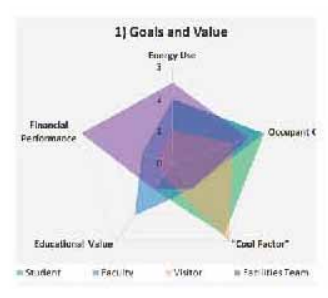

\section{STEP 2. BEHAVIOR CHANGE RESEARCH}

Designing for each user group involves estimating a few broad characteristics, such as energy efficiency goals, typical space use and likely behavior. This is based on observations of existing user behavior, and can be revised at each stage of design, as feedback \& observation of each user groups is gained. 


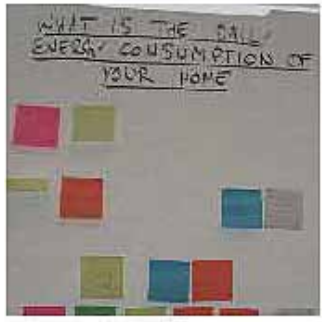

\section{STEP 3. USER RESEARCH \& DESIGN}

Involving users in the process, from initial research and assumptions to design decisions. At GVSU, energy efficiency workshops with users help to engage them in meeting the challenge of energy efficiency, revealing and behavior change observations and ideas.

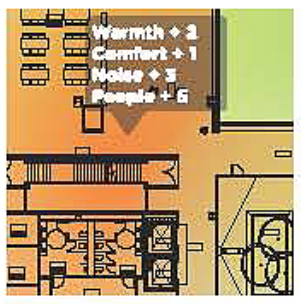

\section{STEP 4. ONGOING FEEDBACK \& OBSERVATION}

Once built, the new GVSU library will support an ongoing energy efficient occupancy, which will provide feedback on performance and assessment of energy impact. Lessons learnt, new ideas and future changes will be captured in this step, for future use.
This understanding allows for specific influential design steps to be taken, targeting each users' new patterns of behavior according to the behavior model. The intended influence for users of this space is a reinforce existing behavior, in an ongoing manner. The strategy for influence in these spaces, with this behavior pattern, with this user group is therefore subtly different from other spaces, behaviors and user groups.

The supported behavior change ECM for GVSU Library uses the same Input, Information Architecture and Output methodology outlined previously, including smart metering and software for processing data. Most importantly, the behavior change ECM provides three types of output, user interfaces designed for each space, user type and behavior;

\section{Energy Efficiency Dashboards}

Showing useful $\&$ relevant information for staff $\&$ students to help support small behavior change.

\section{Ambient Energy Displays \& Signage}

Reinforcing the positive message about energy efficiency achievements \& performance between areas.

\section{Public Art}

An energy-focused public art canvas, offering students an opportunity to tell their energy efficiency story through information and design

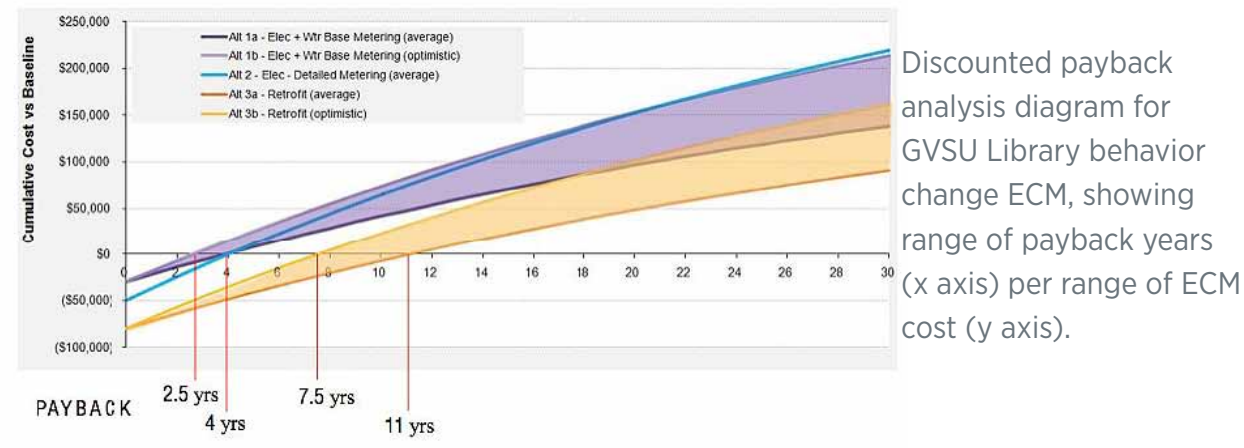

\section{Cost, Savings \& Payback}

High level costing is estimated at $\$ 100,000$. Some of the cost elements are closely tied to the quantity installed (additional sensors incur similar costs), however some elements benefit from an economy of scale.

\begin{tabular}{|l|l|}
\hline Estimated costs include; \\
\hline Smart Metering & $\$ 10,000$ \\
\hline Storage & $\$ 10,000$ \\
\hline Touch Screens & $\$ 20,000$ \\
\hline Public Art Display & $\$ 30,000$ \\
\hline Interface Design & $\$ 30,000$ \\
\hline Subtotal & $\$ 100,000$ \\
\hline
\end{tabular}

These measures are estimated to result in 3.2\% annual energy savings, resulting in a simple payback period of 5-10 years (at an estimated savings of $\$ 15,000$ annually). 


\section{How to get started}

You have energy efficiency goals, needs and users. Where to next.

Implementing simple energy feedback measures can result in consistent and incremental energy cost savings. Providing building occupants of all types with simple, clear, useful and actionable information (following the Fogg Behavior Model, of triggers, ability and motivation), it is possible to deliver a positive behavior change message, encouraging both energy efficiency measures, the benefits these bring and the social proof that others are doing so too.

Bridging the gap between action and consequence, introducing recurring information touch points, small changes can bring not only energy efficiency but long term environmental and economic sustainability. Of the many technologies, theories and approaches to this challenge - some of which have been outlined in this user guide - the most important decisions lie in determining which are appropriate to your situation. Whilst the specific details and context can change, the base roadmap for behavior change measures is described in three simple steps;

\section{Road Map}

\section{Observe Existing Behavior, audit energy use and understand the energy profile.}

This is important in defining the nature of the problem. Identify existing data sources available for observation and use, engage with building occupants about potential energy efficiency initiatives (to communicate potential benefits and learn of any initiatives already in place) and observe behavior to gauge a level of 'willingness to change'. This first step should reoccur throughout the next 3 steps, and again once the behavior change ECM is in place. Good observation will greatly inform analysis and design.

\section{Analyze the data and observations collected, create an energy model and assess areas with high potential for a return on efforts.}

Look for areas with high energy use profiles, perhaps even at odd times during the day, where small step-change efforts could amount to large annual savings. Investigate and understand spatial use for each user type, then compare that with energy use profiles for each space, to identify i.) target user groups, ii.) key behaviors to trigger, and iii.) useful information to lower the threshold to action. This step is to be informed by observation and design, and should be revisited or updated when new information comes to hand. During this step (indeed during this whole process), it's important to inform and engage with the building occupants, as they are the end user not only of the building but the behavior change measures being developed. Engaging with the end user will help confirm or change assumptions made.

\section{Design for each user type and desired behavior outcome.}

Having identified user types, areas of energy savings opportunity, appropriate behavior change triggers, the next step is to design for behavior change. This includes all elements of Informatics technologies (Input, Storage \& Processing, Output), the information architecture, interface design. At each point in the design step, the prior two steps should be reconsulted, to confirm or revise assumptions made earlier. This step is user-centred, meaning prototype designs need to be given to users to see, touch and interact with— to better inform which messages work.
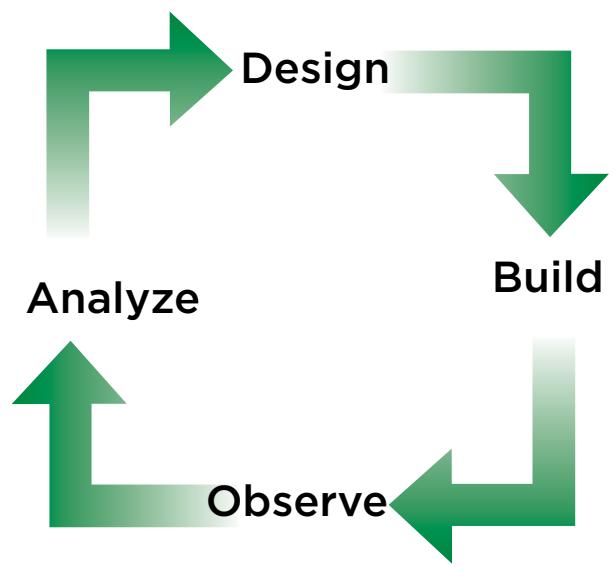

\section{THINGS TO CONSIDER}

- Including a budget for ongoing maintenance and repair of hardware (interface and infrastructure)

- Including a budget for the ongoing behavior change messaging (for a 1, 2, 5,10 year period)

- Including a budget to allow for growing data storage space or needs which emerge over time.

- Including flexibility to allow for future additions, modifications to the system. 


\title{
Industry \& Academia Contacts
}

\author{
Dr. BJ Fogg, Stanford U. \\ Kath Straub, Usability.org \\ Shanah Trevenah, U. Hawaii \\ David Lehrer, UC Berkeley
}

\section{References}

Brown, Z., Cole, R., O'Shea, M., Robinson, J., New Expectations in Delivering Sustainable Buildings, PLEA Conference on Passive and Low Energy Architecture, Québec City, 2009

Farhar, B., Fitzpatrick, C., Effects of Feedback on Residential Electricity Consumption: A Literature Review, Solar Energy Research Institute, 1989

Annual Energy Review 2009, U.S. Energy Information Administration, 2009

Fogg, BJ. \& Hreha, J., Behavior Wizard: A Method for Matching Target Behaviors with Solutions, Persuasive Technology Lab, Stanford University, 2010

Carlsson, F., Kataria, M., Krupnick, A., Lampi, E., Löfgren, A.,Qin, P., Chung, S., Sterner, T., Paying for Mitigation: A Multi-Country Study, 2009.

Petersen, J, Shunturov, V, Janda, K, Platt, G, and Weinberger, K, 2007, Dormitory Residents Reduce Electricity Consumption when Exposed to Real-Time Visual Feedback and Incentives, International Journal of Sustainability in Higher Education, Vol. 8 No. 1, pp. 16-33

Suriowiecki, J., "No one of us is as smart as all of us", The Wisdom of Crowds, 2004.

Clegg, C., Healey, M., David, M. \& Challenger, R., Understanding and promoting green behaviours in the use of existing buildings, Leeds University Business School, 2008. 


\section{ve ENEROY}

Energy Efficiency \& Renewable Energy
EERE Information Center

1-877-EERE-INF (1-877-337-3463)

www.eere.energy.gov/informationcenter

For more information, visit:

commercialbuildings.energy.gov/alliances
Commercial Building Initiative 